\title{
In-Storage-Psychrophilic-Anaerobic-Digestion (ISPAD) process. Part II: Model Validation
}

\author{
Mahsa Madani-Hosseini \\ Dept. of Building, Civil and Environmental Engineering, Concordia University \\ 1455 de Maisonneuve, Montréal, Canada H3G 1M8 \\ E-mail:m.madani84@gmail.com
}

Catherine N. Mulligan

Dept. of Building, Civil and Environmental Engineering, Concordia University

1455 de Maisonneuve, Montréal, Canada H3G 1M8

E-mail: mulligan@civil.concordia.ca

\begin{abstract}
Suzelle Barrington (Corresponding author)
Dept. of Building, Civil and Environmental Engineering, Concordia University 1455 de Maisonneuve, Montréal, Canada H3G 1M8
\end{abstract}

Tel: 0011-450-773-6155 (603)Ｅmail: suzellebarrington@sympatico.ca

Received: August 7, 2015 Accepted: September 1, 2015

doi:10.5296/emsd.v4i2.8118 URL: http://dx.doi.org/10.5296/emsd.v4i2.8118

\begin{abstract}
In-Storage-Psychrophilic-Anaerobic-Digestion (ISPAD) is a sequentially fed batch treatment system operating at a temperature fluctuating with that of ambient. Because of its specific operation modes and the acclimation of its microbial groups, its microbial kinetics were determined from laboratory data, and a specific mathematical model was developed to simulate its process and to optimize its management. The objective of this study is therefore to validate this ISPAD model using further laboratory data obtained from batch tests conducted in flasks. For this purpose, glucose at $630 \mathrm{mg} / \mathrm{L}$, was fed to 8 -year-old ISPAD inoculum and digested at $18{ }^{\circ} \mathrm{C}$. Changes in glucose, VFAs and $\mathrm{pH}$ were monitored along
\end{abstract}


with biogas production. The cross-validated coefficient of determination $\left(Q^{2}\right)$ was used to determine the fit between the model prediction and the experimental values. The ISPAD model was able to strongly predict glucose degradation, VFAs, $\mathrm{pH}$, and methane. However, the model weakly predicted the early $\mathrm{CO}_{2}$ changes over time, likely because of its water solubility.

Keywords: Anaerobic process; Biogas; Modelling; Kinetics parameters; Psychrophilic; Validation

\section{Introduction}

In-Storage-Psychrophilic-Anaerobic-Digestion (ISPAD) consists of a wastewater storage tank converted into an anaerobic digester by means of an airtight floating geo-membrane cover. This anaerobic digestion (AD) system was developed for Canadian climatic conditions to improve system feasibility, reduce odours, conserve nitrogen and produce biogas. The ISPAD system is a long term sequentially fed batch operation functioning under ambient temperature, where wastewater is added sequentially over the treatment period of at least 100 days. Using as base the Keshtkar, Ghaforian, Abolhamd, and Meyssami (2001) model developed for batch systems, a new mathematical model was developed to predict the specific behaviour of the ISPAD process (M. Madani-Hosseini, S. Barrington, \& C. Mulligan, 2014a; M. Madani-Hosseini, S. Barrington, \& C. Mulligan, 2014b). The proposed model was calibrated with experimental data obtained with ISPAD inoculum fed glucose as substrate.

The ISPAD model differs from that of Keshtkar et al. (2001), by using functions specific to low temperature $\mathrm{AD}$ such as determining the activity of the two main groups of methanogens, acetoclastic and hydrogenotrophic, and; including a temperature function for the maximum microbial growth rate, $\mu_{\max }$, and the acid/base dissociation constant $\left(K_{a}\right)$. The developed ISPAD model was found to predict glucose evolution with an $\mathrm{R}$ value of 0.95 to 0.98 , methane production with an $\mathrm{R}$ value of 0.78 to $0.98, \mathrm{pH}$ regime with an $\mathrm{R}$ value of 0.60 to 0.95 and acetate evolution with an $\mathrm{R}$ value of 0.69 to 0.95 .

However, this ISPAD model requires validation to check its predictive capacity. Two types of validation methods are found in the literature, direct and cross validation. Both validation methods can be used if sufficient data is available to produce two subsets, one for parameter identification and direct validation, and the other for cross validation.

In direct validation, the model is tested with data used for parameter identification. A good test in direct validation is based on residuals analysis such as the correlation coefficient $(R)$.

The correlation coefficient $(R)$ has been used alone to evaluate model fit in several studies (Flotats, Palatsi, Ahring, \& Angelidaki, 2006; Palatsi et al., 2010; Redzwan \& Banks, 2004). Madani-Hosseini et al. (2014a) used the $R$ value to check the predictive quality of the 
developed ISPAD model. The results showed that the $R$ values for biogas generation, glucose, VFAs, and $\mathrm{pH}$ ranged from 0.57 to 0.98 , indicating reasonable prediction. Although the model may provide a reasonable fit with respect to the calibration data, it may perform poorly when asked to predict different conditions. As AD is a complicated multi-stage dynamic process, the model should be validated to truly represent the kinetic of the system through obtained kinetic constants. Therefore, cross validation is needed to test the model using different operating condition. Cross validation was applied to check the ADM1 model validity in several studies (Boubaker \& Ridha, 2008; Fezzani \& Cheikh, 2009; Ozkan - Yucel \& Gökçay, 2010; Souza, Carvajal, Donoso-Bravo, Peña, \& Fdz-Polanco, 2013). For example, Boubaker and Ridha (2008) used the ADM1 model to check its applicability for mesophilic anaerobic co-digestion of olive mill wastewater with olive mill solid wastes. Experimental results of the mesophilic anaerobic co-digestion of olive mill wastewater with influent total COD of $56 \mathrm{~g} / \mathrm{L}$ were used for model calibration. The calibrated model was cross-validated with the experimental results using an influent total COD of 24 and $80 \mathrm{~g} / \mathrm{L}$ to check the model predictability. Souza et al. (2013) determined the feasibility of using biochemical methane production (BMP) tests as a data source for ADM1 model calibration. The calibrated model was then cross-validated with continuous digesters data sets.

The principal objective of this study was to validate the ISPAD model. Accordingly, laboratory experiments were conducted using inoculum from an 8-year-old ISPAD system and glucose was used as substrate. The inoculum characteristics were similar to that used to calibrate the ISPAD model using the Simulink/Matlab software. As opposed to calibration conditions, the validation laboratory tests used a double glucose concentration of $630 \mathrm{mg} / \mathrm{L}$, but the same temperature of $18{ }^{\circ} \mathrm{C}$. During the laboratory experiments, glucose, VFAs and $\mathrm{pH}$ changes were monitored along with biogas production.

\section{Material and Methods}

\subsection{Experimental Data}

For the model validation, batch experiments were conducted at $18{ }^{\circ} \mathrm{C}$ in the laboratory using an inoculum obtained from an 8-year-old (2013) field ISPAD. The field ISPAD is used to treat the manure produced by a swine farrowing unit, in the central part of the Province of Quebec, Canada, near Sherbrooke.

The batch experiments produced using the ISPAD inoculum generated curves for glucose degradation and VFAs and $\mathrm{CH}_{4}$ production over time at temperature $18{ }^{\circ} \mathrm{C}$. All samples were duplicated and the results were averaged. The $250 \mathrm{ml}$ test bottles were filled with $150 \mathrm{ml}$ of ISPAD inoculum $(5.3 \mathrm{gVS} / \mathrm{L})$ and $15 \mathrm{ml}$ of $7000 \mathrm{mg} / \mathrm{L}$ of glucose solution. The total volume of liquid in each $250 \mathrm{ml}$ bottle was therefore $165 \mathrm{ml}$ with a VS and glucose concentration of $4.8 \mathrm{~g} / \mathrm{l}$ and $630 \mathrm{mg} / \mathrm{L}$, respectively. Duplicate control bottles were prepared with ISPAD inoculum and water instead of glucose. Bottles were capped, sealed and flushed with $\mathrm{N}_{2}$ gas to establish anaerobic conditions, before starting the AD process and monitoring glucose and VFAs concentrations, $\mathrm{pH}$ changes and $\mathrm{CH}_{4}$ production. All bottles were placed in an incubator maintained at $18{ }^{\circ} \mathrm{C}$. The mixture was 


\section{1) Macrothink}

shaken by hand once a day.

Samples of $2 \mathrm{ml}$ were regularly withdrawn from the bottle headspace for gas production analysis using a gas chromatograph while gas production was monitored until gas production ceased, using a water displacement apparatus. Also, $2 \mathrm{ml}$ liquid samples were removed from each bottle at specified time intervals to monitor $\mathrm{pH}$, and glucose and VFA concentrations.

The ISPAD inoculum was analysed according to standard methods (Eaton \& Franson, 2005) to establish: Solids (TS, VS, TSS, and VSS) and pH. To measure COD, the commercial COD test kit for ultra-high rate COD were used (DR/4000, HACH Corp). Anions including $\mathrm{NO}_{3}{ }^{2-}$, $\mathrm{NO}_{2}{ }^{-}$, and $\mathrm{PO}_{4}{ }^{3-}$ and cation of $\mathrm{NH}_{4}{ }^{+}$and total VFAs were determined by $\mathrm{HACH}$ kit/high rate.

To monitor gas production from the batch tests, the biogas composition $\left(\mathrm{CH}_{4}\right.$, and $\left.\mathrm{CO}_{2}\right)$ was measured by injecting the $2 \mathrm{ml}$ samples into a Gas Chromatograph (Varian, model 3800) equipped with TCD detector and CARBOXEN 1010 PLOT (capillary column) from SUPELCO, $30 \mathrm{~mm} \times 0.53 \mathrm{~mm}$ column. The carrier gas was Helium/argon. The column temperature was held at $50-100{ }^{\circ} \mathrm{C}$ for $5{ }^{\circ} \mathrm{C} / \mathrm{min}$. The injection flow was $5 \mathrm{ml} / \mathrm{min}$.

The liquid samples were analyzed for glucose concentration, total VFAs, and $\mathrm{pH}$. The glucose concentration was measured by the colorimetric method (Lever, 1972).

\subsection{Statistical Procedure}

To validate the model, the ISPAD model was run using an operating temperature of $18{ }^{\circ} \mathrm{C}$, and a glucose concentration of $630 \mathrm{mg} / \mathrm{L}$. The model was run using the Simulink/Matlab software and the kinetic parameters obtained through model calibration (Madani-Hosseini et al., 2014a). The model prediction was then compared with experimental data using the cross-validated coefficient of determination $\left(Q^{2}\right)$ as statistical parameters (Eq. 1). The cross-validated coefficient of determination $\left(Q^{2}\right)$ quantifies the quality of the fit between the model prediction and the experimental values and the ability to correctly predict new data, respectively.

$$
Q^{2}=1-\frac{\sum_{i=1}^{n}\left(y_{i}-\widehat{y_{i}}\right)^{4}}{\sim m} \quad Q^{2} \leq 1
$$

where $\mathrm{n}, y_{i}, \widehat{y_{k}}$, and $\bar{y}$ represent the number of data, experimental data, model predicted data, and mean of data, respectively. $\mathrm{A}^{2}$ value approaching 1 shows a good prediction for the model. The $\mathrm{Q}^{2}$ values testing the validation were compared to the $R^{2}$ values used to test the calibration of the ISPAD model (Madani-Hosseini et al., 2014a). The $Q^{2}$ and $R^{2}$ 
are the same parameters with different names to distinguish between validation and calibration.

\section{Results and Discussion}

\subsection{Inoculum Characterization}

The analytical results of analyses performed on the 8-year old ISPAD inoculum are presented in Table 1.

Table 1. Characteristics of the experimental inoculum

\begin{tabular}{|c|c|c|c|c|}
\hline \multicolumn{2}{|c|}{ Characteristic } & Unit & Value & $\mathrm{STD}^{1}$ \\
\hline \multirow{6}{*}{ Solids } & TS & $g / L$ & 8.74 & 0.27 \\
\hline & VS & $g / L$ & 5.29 & 0.35 \\
\hline & FS & $g / L$ & 3.45 & 0.13 \\
\hline & VSS & $g / L$ & 4.01 & 0.09 \\
\hline & VDS & $g / L$ & 1.28 & 0.27 \\
\hline & TSS & $g / L$ & 4.17 & 0.26 \\
\hline \multicolumn{2}{|l|}{$\mathrm{pH}$} & - & 8.22 & 0.10 \\
\hline Total VFAs & & $g \mathrm{HOAC} / L$ & 1.19 & 0.25 \\
\hline COD & & $g / L$ & 6.10 & 0.21 \\
\hline \multirow{4}{*}{ Anions } & $\mathrm{NO}_{2}^{-}$ & $g / L$ & 0.01 & 0.00 \\
\hline & $\mathrm{NO}_{3}^{-}$ & $g / L$ & 0.08 & 0.001 \\
\hline & $\mathrm{PO}_{4}^{3-}$ & $g / L$ & 0.47 & $\begin{array}{l}0.047 \\
\end{array}$ \\
\hline & $\mathrm{SO}_{4}^{2-}$ & $g / L$ & 0.83 & 0.035 \\
\hline Cation & $\mathrm{NH}_{4}^{+}$ & $g / L$ & 1.04 & 0.045 \\
\hline
\end{tabular}

The 8-year old ISPAD inoculum had fewer solids than 7-year-old field ISPAD inoculum used for calibration. For example, the VS of 8-year old ISPAD inoculum was half of that of 7-year-old field ISPAD inoculum, because the sampling was conducted without reaching the bottom layer of settled solids. The other components such as $\mathrm{pH}, \mathrm{COD}$, anions, and cations did not change significantly over a year. 


\subsection{Model Prediction and Validation}

Figures 1 to 4 present the results of the laboratory experiment monitoring the glucose and VFAs concentrations, the biogas generation and the changes in $\mathrm{pH}$, along with the model prediction. The performance of the model in predicting the results was determined using the statistical parameters of $\mathrm{Q}^{2}$. The results showed that $\mathrm{Q}^{2}$ values ranged from 0.49 to 0.98 . Methane prediction had the highest $\mathrm{Q}^{2}$ value of 0.98 . However, $\mathrm{CO}_{2}$ prediction had the lowest $\mathrm{Q}^{2}$ value of 0.49 , likely because of the high water solubility of $\mathrm{CO}_{2}$. The calibration results showed that the coefficient of determination $\left(R^{2}\right)$ were in the range of 0.47 to 0.96 (Table 2). Table 2 shows that the model prediction ability increased through validation for $\mathrm{pH}$, $\mathrm{CH}_{4}$, and VFAs.

Table 2. Values of $R^{2}$ from calibration and $Q^{2}$ from cross validation

\begin{tabular}{|l|l|l|}
\hline Component & $\boldsymbol{R}^{\mathbf{2}}$ & $\boldsymbol{Q}^{\mathbf{2}}$ \\
\hline Glucose & 0.96 & 0.76 \\
\hline VFA & $0.65,0.54,0.47^{*}$ & 0.85 \\
\hline $\mathrm{CH}_{4}$ & 0.92 & 0.98 \\
\hline $\mathrm{CO}_{2}$ & 0.65 & 0.49 \\
\hline $\mathrm{pH}$ & 0.51 & 0.78 \\
\hline Note: *For propionate, butyrate, and acetate, respectively. \\
\hline
\end{tabular}

The ISPAD model predicted the glucose experimental data with a $Q^{2}$ value of 0.76 . However, the model calibration showed a better $R^{2}$ value of 0.96 . For the glucose concentration, the model prediction ability decreases over time, while at the beginning the model strongly predicted the glucose consumption. This is likely the result of low glucose concentrations after 3 days of experimentation, and error in the analytical results (Figure 1).

Figure 2 shows the model prediction ability for total VFAs. The model predicted the ISPAD system with the $Q^{2}$ value of 0.85 , which is higher than the $R^{2}$ value for calibration of individual VFAs, propionate, butyrate, and acetate with $R^{2}$ values of $0.65,0.54$, and 0.47 , respectively. There are some occasional discrepancies between model prediction and the experimental data. The first discrepancy resulted from the one-day lag phase, where the model indicated a high VFA production from the start, whereas the experimental data 
indicated that VFA production started after day 1. Also after day 5, VFA levels were low leading to some analytical error in the experimental data. This resulted in a general ISPAD model over predicting total VFAs.

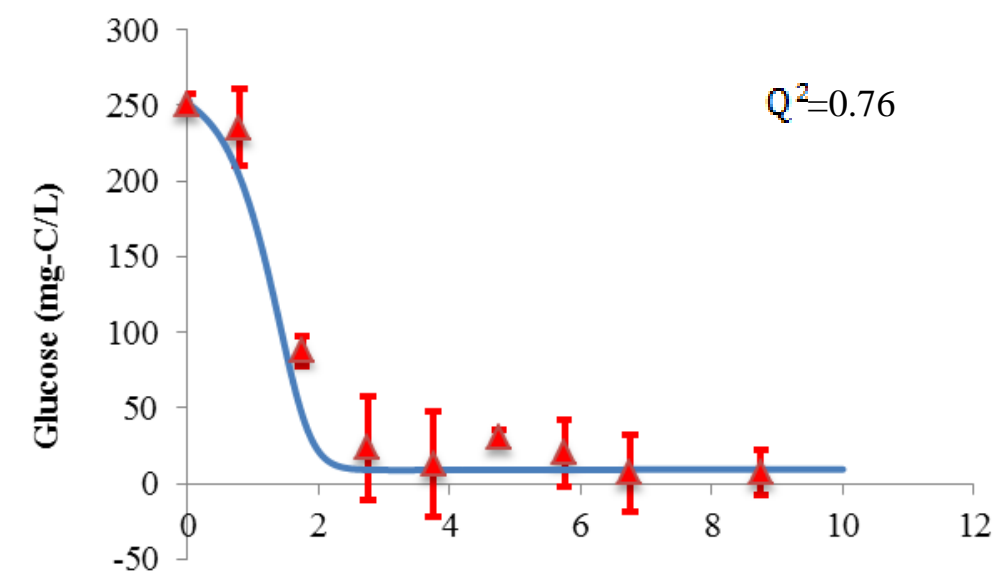

Time (day)

Figure 1: Simulation of glucose evolution at $18{ }^{\circ} \mathrm{C}$ digested by the ISPAD inoculum.

Experimental data, triangle; model prediction, line. Note: Data points represent the average of two replicates and error bars represent $+/$ - one standard deviation.

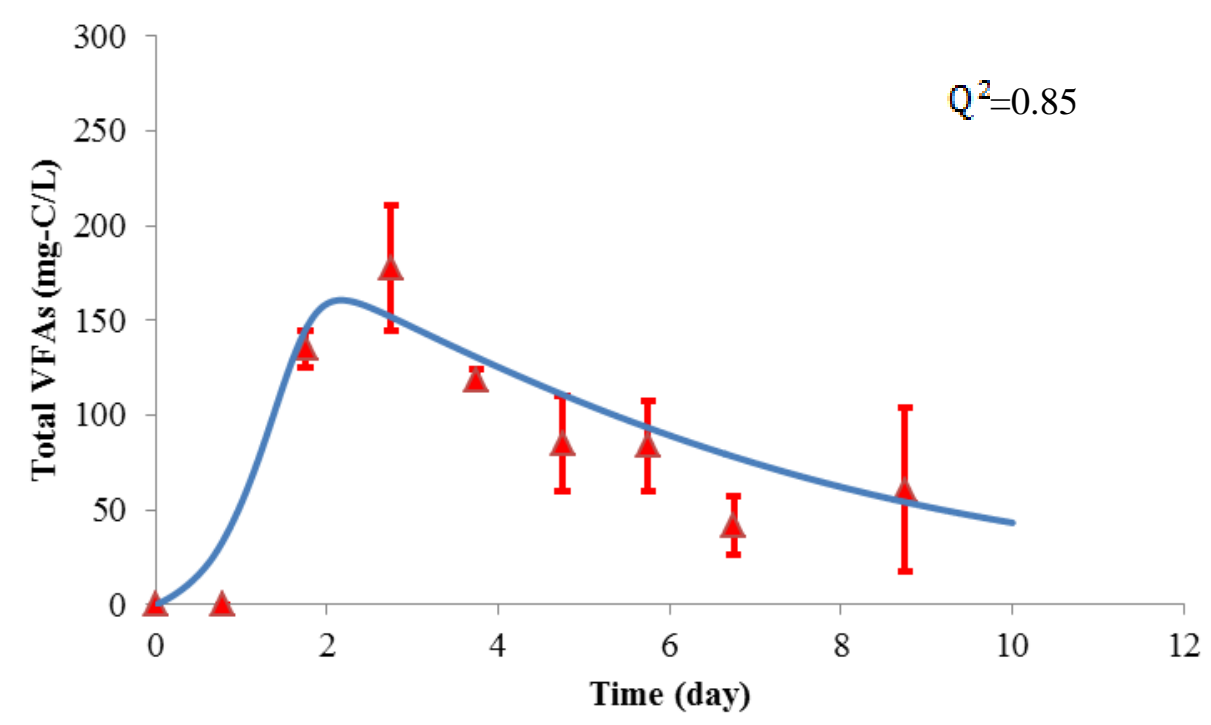

Figure 2: Simulation of VFAs production from glucose degradation at $18{ }^{0} \mathrm{C}$ digested by the ISPAD inoculum. Experimental data, triangle; model prediction, line. Note: Data points represent the average of two replicates and error bars represent + /- one standard deviation.

The ISPAD model was capable of accurately predicting $\mathrm{CH}_{4}$ production, with a $\mathrm{Q}^{2}$ value of 0.98 (Figure 3 ), very close to the $R^{2}$ value for calibration of 0.92 . The ISPAD prediction 


\section{Ml Macrothink}

ability for $\mathrm{CH}_{4}$ increased over time, as the model tended to under estimate values in the beginning, as also observed with the model calibration. This early over-prediction for both calibration and validation curve resulted from a one-day lag phase in $\mathrm{CH}_{4}$ production, as the inoculum had been stored at $4{ }^{\circ} \mathrm{C}$ for several months before being used.

The ISPAD model was not so accurate in predicting $\mathrm{CO}_{2}$ especially at the beginning of the assay because of its absorption by the wastewaters, being highly soluble as compared to $\mathrm{CH}_{4}$ (Figure 3). After 3 days, the calibration curve provided a better prediction of the experimental data better than validation curve.
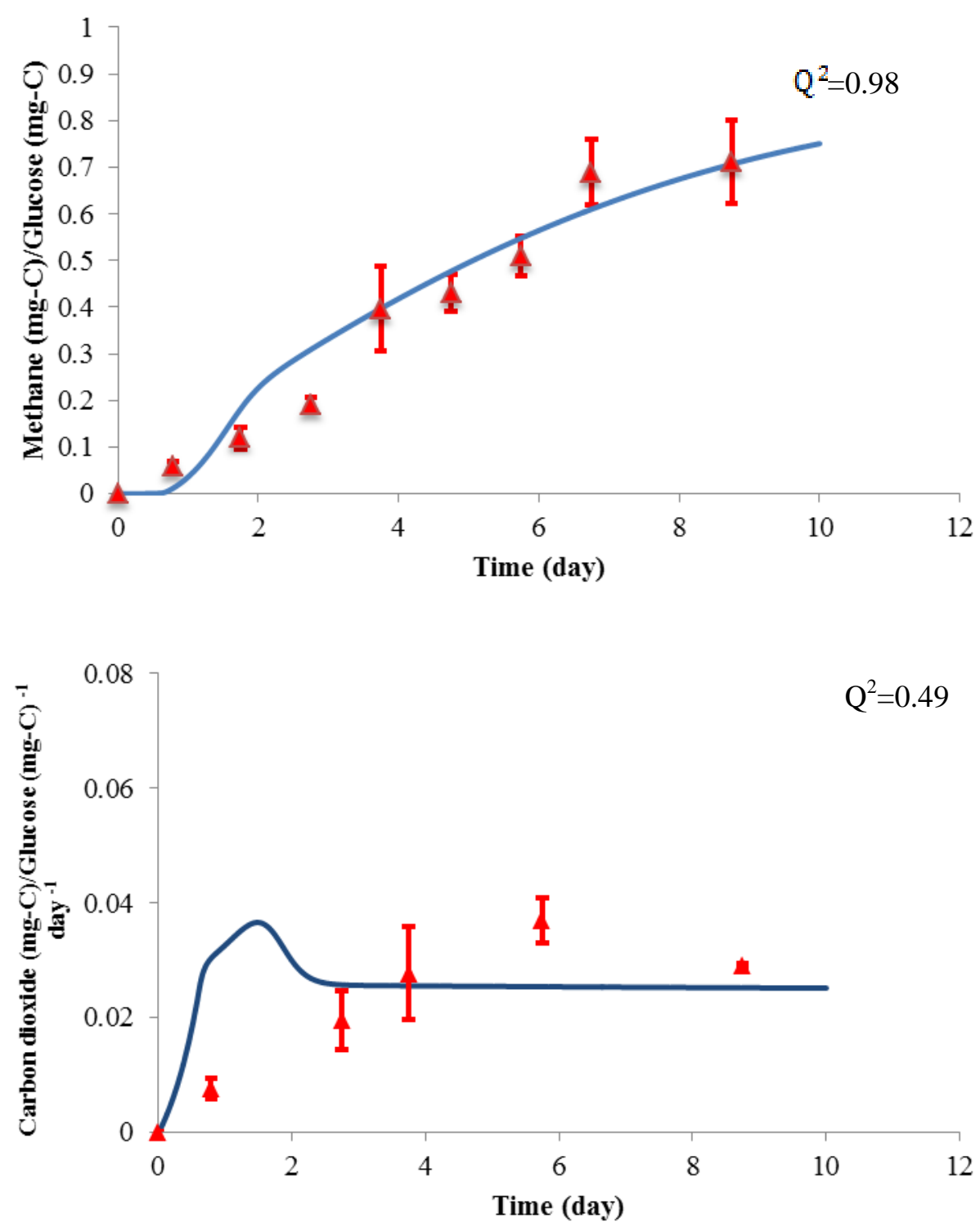

Figure 3: Simulation of biogas production from glucose degradation at $18{ }^{0} \mathrm{C}$ by digested by the ISPAD inoculum. Experimental data, triangle; model prediction, line. Note: Data points represent the average of two replicates and error bars represent $+/$ - one standard deviation.

The model predicted the $\mathrm{pH}$ of ISPAD system with a $\mathrm{Q}^{2}$ of 0.78 . However, some significant 


\section{Macrothink}

discrepancies between model prediction and the experimental data were observed specifically at the beginning of the essay (Figure 4). The model predicted a fast drop in $\mathrm{pH}$ right from the start, while the experimental data demonstrated a slower drop, likely as a result of the one-day lag phase observed in VFA production. The validation curve was better able to predict $\mathrm{pH}$ changes, with a $\mathrm{Q}^{2}$ value of 0.78 as compared to the calibration $\mathrm{R}^{2}$ value of 0.51 .

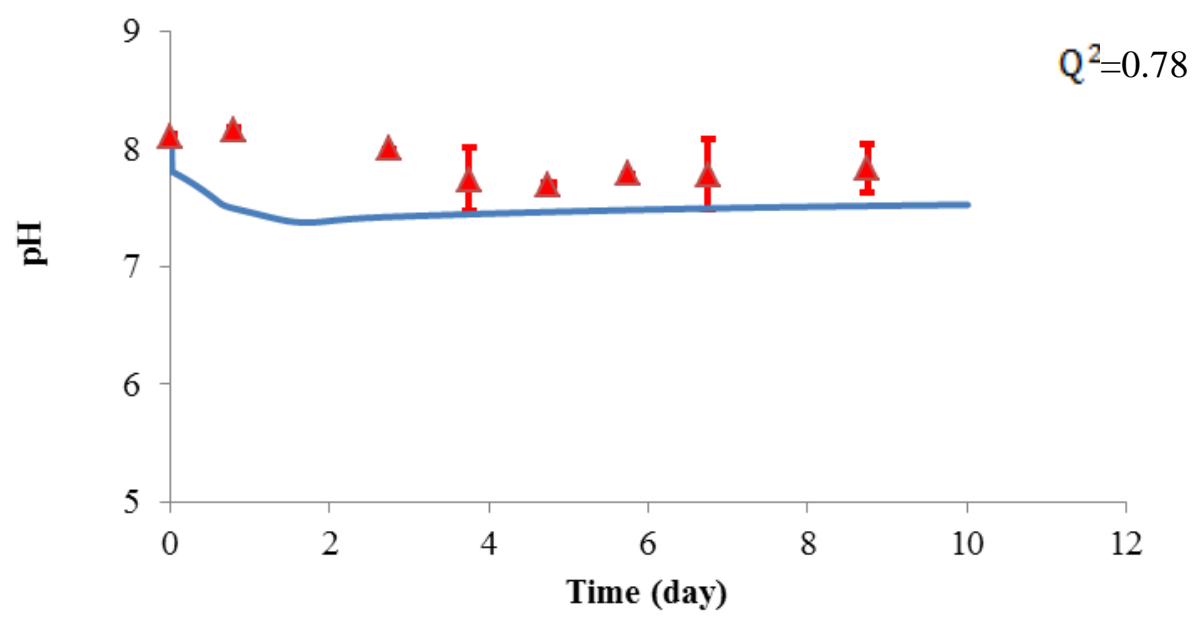

Figure 4: Simulation of $\mathrm{pH}$ evolution from glucose degradation at $18{ }^{\circ} \mathrm{C}$, digested by the ISPAD inoculum. Experimental data, triangle; model prediction, line. Note: Data points represent the average of two replicates and error bars represent $+/$ - one standard deviation.

The ISPAD model was able to properly predict the behavior of the ISPAD system during the validation process. However, the several assumptions made while building the ISPAD model introduce some prediction limitations:

- all parameters are calibrated with inoculum from the same ISPAD system fed swine manure;

- only glucose was tested as substrate, and a change in substrate may not be modeled as well;

- The ISPAD model was designed to predict the performance of batch fed systems;

- The ISPAD model was calibrated by laboratory scale data, and needs to be validated using prototype and field scale experimental data.

\section{Conclusion}

The capacity of the model to predict ISPAD behaviour was validated at $18{ }^{\circ} \mathrm{C}$ using laboratory data obtained with a substrate concentration twice as high as that used for its calibration. In general, the cross-validation procedure produced a $\mathrm{Q}^{2}$ value over 0.65 , 
indicating few discrepancies with both over- and under-prediction. Therefore, the kinetic parameters obtained by Madani-Hosseini et al. (2014a) and the ISPAD model built for a batch fed system produced a tool capable of predicting the behaviour of ISPAD inoculum when glucose was used as substrate under temperatures ranging from 4 to $35^{\circ} \mathrm{C}$. This model needs to be further refined using data obtained from prototype testing and field applications.

\section{Acknowledgments}

The authors acknowledge the financial contribution of Geomembrane Technology Inc. (Fredericton, New Brunswick, Canada) and the Natural Science and Engineering Research Council of Canada (NSERC) and Concordia University.

\section{References}

Boubaker, F., \& Ridha, B. C. (2008). Modelling of the mesophilic anaerobic co-digestion of olive mill wastewater with olive mill solid waste using anaerobic digestion model No. 1 (ADM1). Bioresource technology, 99(14), 6565-6577.

Eaton, A. D., \& Franson, M. A. H. (2005). Standard Methods for the Examination of Water \& Wastewater. Washington, D.C.: American Public Health Association.

Fezzani, B., \& Cheikh, R. B. (2009). Extension of the anaerobic digestion model No. 1 (ADM1) to include phenolic compounds biodegradation processes for the simulation of anaerobic co-digestion of olive mill wastes at thermophilic temperature. Journal of hazardous Materials, 162(2), 1563-1570.

Flotats, X., Palatsi, J., Ahring, B., \& Angelidaki, I. (2006). Identifiability study of the proteins degradation model, based on ADM1, using simultaneous batch experiments. Water Science \& Technology, 54(4), 31-39.

Keshtkar, A., Ghaforian, H., Abolhamd, G., \& Meyssami, B. (2001). Dynamic Simulation of Cyclic Batch Anaerobic Digestion of Cattle Manure. Bioresource Technology, 80(1), 9-17.

Lever, M. (1972). A New Reaction for Colorimetric Determination of Carbohydrates. Analytical Biochemistry, 47(1), 273-279.

Madani-Hosseini, M., Barrington, S., \& Mulligan, C. (2014a). In-Storage-Psycrophilic-Anaerobic-Digestion (ISPAD) process. Part I: Model Development and Calibration. Presented for publication.

Madani-Hosseini, M., Barrington, S., \& Mulligan, C. (2014b). Microbial Kinetic for In-Storage-Psychrophilic Anaerobic Digestion (ISPAD). Journal of Environmental Management, 146, 59-68.

Ozkan-Yucel, U. G., \& Gökçay, C. F. (2010). Application of ADM1 model to a full-scale anaerobic digester under dynamic organic loading conditions. Environmental technology, 31(6), 633-640.

Palatsi, J., Illa, J., Prenafeta-Boldú, F. X., Laureni, M., Fernandez, B., Angelidaki, I., \& Flotats, X. (2010). Long-chain fatty acids inhibition and adaptation process in anaerobic 


\section{Macrothink}

thermophilic digestion: Batch tests, microbial community structure and mathematical modelling. Bioresource Technology, 101(7), 2243-2251.

Redzwan, G., \& Banks, C. (2004). The Use of a Specific Function to Estimate Maximum Methane Production in a Batch-Fed Anaerobic Reactor. Journal of Chemical Technology and Biotechnology, 79(10), 1174-1178.

Souza, T. S. O., Carvajal, A., Donoso-Bravo, A., Peña, M., \& Fdz-Polanco, F. (2013). ADM1 calibration using BMP tests for modeling the effect of autohydrolysis pretreatment on the performance of continuous sludge digesters. Water Research, 47(9), 3244-3254.

\section{Copyright Disclaimer}

Copyright for this article is retained by the author(s), with first publication rights granted to the journal.

This is an open-access article distributed under the terms and conditions of the Creative Commons Attribution license (http://creativecommons.org/licenses/by/3.0/). 